\title{
FORMAÇÃO ACADÊMICA NA EDUCAÇÃO SUPERIOR: análise da Produção de Conhecimento nos Periódicos Qualis A1 e A2 (2010-2018) ${ }^{1}$
}

\author{
Uyguaciara Veloso Castelo Branco
}

\section{Resumo}

O artigo apresenta uma revisão teórica sobre a formação acadêmica na Educação Superior, enquanto subcategoria que compõe a ambiência de ensino-aprendizagem, a partir da análise da produção acadêmica disponível nos periódicos da área de Educação, com classificação Qualis A1 e A2 (CAPES). Como recorte temporal, foram analisados artigos produzidos entre 2010-2018. Foram catalogados 266 artigos de 14 periódicos em língua portuguesa. Os descritores utilizados, inicialmente, foram: educação superior e evasão ou permanência ou relação professor/a - aluno/a. Foram organizados dados bibliográficos da produção, resumos e palavras-chave que, após análise, permitiram a seleção de 103 artigos. Foram sistematizados os principais aspectos apresentados em cada um dos artigos, possibilitando identificar elementos importantes na configuração da ambiência de ensino-aprendizagem na educação superior, envolvendo discussões sobre: currículo dos cursos de graduação, metodologias, avaliação e dimensão afetivo-cognitiva no ambiente acadêmico. Para fins deste artigo, foi apresentada a subcategoria formação acadêmica, a partir de importantes elementos teórico-metodológicos, como: competência, capital simbólico, engajamento, formação acadêmica e mercado de trabalho, métodos ativos de aprendizagem e modelo de avaliação institucional. Os trabalhos referenciados no presente estudo se constituem em importantes instrumentos para ampliação e verticalização dos estudos, com novos elementos para a construção do conhecimento.

Palavras-chave: educação superior; produção de conhecimento; periódicos qualis/capes; formação acadêmica.

HIGHER EDUCATION ACADEMIC TRAINING: Knowledge Production Analysis of A1 and A2 Qualis Periodics (2010 to 2018)

\begin{abstract}
This paper presents a theoretical review of academic training in Higher Education, as a sub-category that comprises the teaching-learning environment, based on the analysis of academic production available in education journals, classified as Qualis A1 and A2 (CAPES). As a temporal cut, we analyzed articles produced from 2010 to 2018. In total 266 articles from 14 Portuguese-language journals were catalogued. The descriptors used initially were higher education and dropout, permanence or teacher-student relationship. Bibliographic data of the production, abstract and keywords were organized and, after analysis, allowed the selection of 103 articles. The main aspects presented in each article were systematized, enabling the identification of important elements in the configuration of the teaching-learning environment in higher education, involving discussions about university graduate curriculum, methodologies, assessment and the affective-cognitive dimension in the academic environment. For the purposes of this paper, the sub-category academic training was presented, based on important theoretical-methodological elements, such as: competence, symbolic capital, engagement, academic education and the job market, active learning methods and institutional evaluation model. The works referenced in the present study are important instruments for the expansion and verticalization of studies, with new elements for the construction of knowledge.
\end{abstract}

\footnotetext{
${ }^{1} \mathrm{O}$ artigo foi construído como parte do Projeto de Pós-Doutorado, realizado junto ao Instituto de Creatividad e Innovaciones Educativas da Universitat de València (España), sob a supervisão dos Profs. Drs. Francesc Jesús Hernàndez I Dobón e Alícia Villar Aguilés.
} 
DOI: $10.12957 /$ teias.2022.56040

Keywords: higher education; knowledge production; qualis/capes periodicals; academic training.

\section{FORMACIÓN ACADÉMICA EN LA EDUCACIÓN SUPERIOR: Análisis de la Producción de Conocimientos en Revistas Qualis A1 y A2 (2010-2018)}

Resumen

Este artículo presenta una revisión teórica de la formación académica en la Educación Superior, como una subcategoría que conforma el entorno de enseñanza, basada en el análisis de la producción académica disponible en revistas educativas, clasificadas como Qualis A1 y A2 (CAPES). Como recorte temporal, analizamos artículos producidos entre 2010-2018. Se catalogaron 266 artículos de catorce revistas en portugués. Los descriptores utilizados fueron: educación superior y deserción o permanencia o relación profesor-alumno. Los datos bibliográficos de la producción, el resumen y las palabras clave se organizaron y, después del análisis, permitieron la selección de 103 artículos. Los principales aspectos presentados en cada artículo fueron sistematizados, permitiendo la identificación de elementos importantes en la configuración del ambiente de enseñanza-aprendizaje, involucrando discusiones sobre los planes de curso de grado, las metodologías, la evaluación y la dimensión afectivo-cognitiva en el entorno académico. Para los propósitos de este trabajo, se presentó la subcategoría de formación académica, basada en elementos teórico-metodológicos importantes, tales como: competencia, capital simbólico, compromiso, educación académica y mercado laboral, métodos de aprendizaje activo y modelo de evaluación institucional. Los trabajos que se hace referencia en el estudio son instrumentos importantes para las investigaciones, con nuevos elementos para la construcción del conocimiento.

Palabras clave: educación superior; producción de conocimiento; revistas qualis - capes; formación académica.

\section{INTRODUÇÃO}

A preocupação central que norteia esse estudo é discutir e aprofundar os múltiplos fatores que interferem ou contribuem para a permanência (ou seu polo oposto ou elemento contraditório, a evasão ${ }^{2}$ ou abandono ${ }^{3}$ ) na Educação Superior no Brasil. Investigar os fatores que contribuem para a permanência ou para a evasão de alunos/as não é relevante apenas do ponto de vista didático-pedagógico, mas constitui a ordem do dia, quando o tema envolve a busca de eficiência e eficácia no atendimento de uma prestação de serviço, cujo resultado atinge diretamente a vida das pessoas e seu empoderamento social.

Entretanto, é de extrema complexidade a abordagem dessa temática, uma vez que ela envolve não apenas condições antecedentes à entrada do/a aluno/a na educação superior, como também condições de infraestrutura, financiamento, condições psicoafetivas e sociais, dentre estas, a complexa relação professor/a - aluno/a, a partir de dois aspectos fundamentais: a formação acadêmica

\footnotetext{
${ }^{2}$ Morosini e colaboradores (2012, p. 2) definem evasão estudantil “[...] como um fenômeno educacional complexo, que ocorre em todos os tipos de instituição de ensino e afeta o sistema educacional como um todo. Entendida como a perda de alunos/as nos diversos níveis de ensino, a evasão gera consequências sociais, acadêmicas e econômicas, afetando o desenvolvimento humano de todas as nações."

${ }^{3}$ Define-se, como indicador de evasão, o abandono, para fins de cálculo e análise, em estudo anterior (CASTELO BRANCO; JEZINE; NAKAMURA, 2016, p. 278). Nesse sentido, o abandono $\left(A_{i}\right)$ em um determinado ano (i) é calculado como resultado da Matrícula Esperada em um determinado ano $\left(\mathrm{Me}_{\mathrm{i}}=\mathrm{M}_{\mathrm{i}-1}-\mathrm{C}_{\mathrm{i}-1}+\mathrm{I}_{\mathrm{i}}\right.$, sendo: $\mathrm{M}_{\mathrm{i}}=\mathrm{Matrícula}_{\mathrm{a}}$ no ano i $\mathrm{C}_{\mathrm{i}}=$ Concluintes no ano i ; $\mathrm{I}_{\mathrm{i}}=$ Ingressos no ano i), subtraída da Matrícula ocorrida em determinado ano $\left(\mathrm{M}_{\mathrm{i}}\right)$, ou seja, $\mathrm{A}_{\mathrm{i}}=\mathrm{Me}_{\mathrm{i}}-\mathrm{M}_{\mathrm{i}}$.
} 
e a formação docente, como elementos centrais e interrelacionados em um processo de ensinoaprendizagem.

Entende-se, inicialmente, a relação professor/a - aluno/a como uma relação dialógica a ser estabelecida entre quem exerce o papel de professor/a (aquele que ensina) e o/a aprendente $(\mathrm{o} / \mathrm{a}$ aluno/a),

[...] o diálogo é uma exigência existencial. E, se ele é o encontro em que se solidarizam o refletir e o agir de seus sujeitos endereçados ao mundo a ser transformado e humanizado, não pode reduzir-se a um ato de depositar ideias de um sujeito no outro, nem tampouco tornar-se simples troca de ideias a serem consumidas pelos permutantes. (FREIRE, 1987, p. 79).

Nesse sentido, acrescentou-se duas dimensões de análise a essa relação: a formação docente e a formação acadêmica (dos/as aprendentes), em ambos os processos, interagindo não somente com a dimensão curricular e formal do processo de formação propriamente dito, mas também com as inter-relações que se estabelecem entre sujeitos em sua rede de relacionamentos e sociabilidades ${ }^{4}$. Nesse sentido, analisou-se o entorno de enseñanza ou a ambiência de ensino-aprendizagem, tentando mapear suas nuances e características intra e inter-relacionadas.

\section{PERCURSO METODOLÓGICO}

Com a finalidade de investigar a relação professor/a - aluno/a e/ou os elementos relativos à formação docente, bem como sua relação direta com a formação acadêmica intencional, dada pelas Instituições de Ensino Superior (IES), enveredou-se na investigação, a partir de uma busca sistemática e seletiva nos indexadores da produção acadêmica, tendo a educação superior como grande guarda-chuvas; os elementos norteadores desta investigação passaram pela discussão sobre evasão/permanência, sendo o elemento de filtro a relação professor/a - aluno/a. Portanto, constituiu-se, como objetivo maior, realizar uma revisão bibliográfico-documental sobre a temática da permanência na Educação Superior no Brasil, analisando a produção no período de 2010 a 2018 dos principais periódicos da área de Educação.

Como percurso metodológico, foi realizada, inicialmente, a análise da produção acadêmica sobre a temática relação professor/a - aluno/a na Educação Superior, nos principais periódicos da área de Educação, privilegiando os artigos das revistas de classificação A1 e A2, segundo os critérios definidos pelo sistema Qualis da Coordenação de Aperfeiçoamento de Pessoal de Nível Superior (CAPES) $^{5}$. Foram realizadas buscas no sistema Scientific Electronic Library Online (Base SCIELO).

Foram catalogados e analisados os artigos produzidos, entre 2010 e 2018, nos seguintes periódicos, da área de Ciências Humanas, Educação e Pesquisa Educacional, Psicologia

\footnotetext{
${ }^{4}$ Compreende-se a categoria rede de sociabilidades, na perspectiva de Sirinelli (2003, p.246): “todo grupo de intelectuais organiza-se a partir de uma sensibilidade ideológica ou cultural comum e de afinidades, que alimentam o desejo e o gosto de conviver".

${ }^{5}$ De acordo com a CAPES, “O Qualis Periódicos é uma das ferramentas utilizadas para a avaliação dos programas de pós-graduação no Brasil. Tem como função auxiliar os comitês de avaliação no processo de análise e de qualificação da produção bibliográfica dos docentes e discentes dos programas de pós-graduação credenciados pela CAPES. Ao lado do sistema de classificação de capítulos e livros, o Qualis Periódicos é um dos instrumentos fundamentais para a avaliação do quesito produção intelectual, agregando o aspecto quantitativo ao qualitativo." Os indicadores variam de A1 (nível mais elevado) até $\mathrm{C}$ (nível mais baixo da qualidade da produção). Disponível em: http://www.capes.gov.br/pt/36-noticias/8331-diretora-da-capes-esclarece-duvidas-sobre-o-qualis-em-artigo. Acesso em: 08 maio. 2019.
} 
Educacional, Psicologia Multidisciplinar e Psicologia Social, listados a partir dos indexadores de busca descritos anteriormente: Avaliação: Revista da Avaliação da Educação Superior (Campinas), Educação \& Sociedade, Educação e Pesquisa, Revista Brasileira de Educação, Psicologia Escolar e Educacional, Revista Brasileira de Estudos Pedagógicos, Psicologia: Ciência e Profissão, Educação \& Realidade, Revista Lusófona de Educação, Revista Portuguesa de Educação, Estudos de Psicologia (Campinas), Psicologia: Teoria e Pesquisa, Cadernos CEDES, Psicologia \& Sociedade.

A coleta dos dados foi realizada, como parte do estágio pós-doutoral, em 2019-2020, razão pela qual utilizamos como término do recorte o ano de 2018. O início do recorte, em 2010, atendeu ao princípio censitário de década, aliado ao interesse em investigar a produção bibliográfica mais robusta sobre a temática da permanência, disponível na década posterior às políticas de expansão da Educação Superior, ocorridas entre 2003 e 2007, com os Programas Expandir e Reestruturação e Expansão das Universidades Federais (REUNI).

A análise dos artigos identificados foi feita a partir dos seguintes descritores, definidos a priori: 1) educação superior e 2) evasão ou 3) permanência ou 4) relação professor/a - aluno/a. Foi feita a catalogação das 266 produções listadas, com a organização dos dados bibliográficos da produção, seu respectivo resumo e palavras-chave, em uma ficha catalográfica confeccionada pela pesquisadora, conforme layout a seguir.

Figura 1. Layout da ficha catalográfica

\begin{tabular}{|c|c|c|c|c|}
\hline $\mathrm{N}^{\circ}$ & $\begin{array}{c}\text { REFERÊNCIA } \\
\text { COMPLETA }\end{array}$ & RESUMO & $\begin{array}{c}\text { PALAVRAS- } \\
\text { CHAVE }\end{array}$ & TEMÁTICA \\
\hline
\end{tabular}

Fonte: Pesquisa realizada, 2020.

Após a leitura dos resumos e das palavras-chave, foram selecionados um total de 103 artigos que tratavam da temática relação professor/a - aluno/a, abordando elementos para a evasão ou permanência na educação superior. Nesse momento, foi incorporada a palavra-chave formação docente e formação acadêmica, para melhor compreender a relação professor/a - aluno/a na educação superior. A partir desses descritores, foram elencados os principais aspectos apresentados em cada um dos artigos, possibilitando uma análise bastante abrangente sobre a produção recente relacionada à temática, em língua portuguesa, possibilitando identificar elementos importantes na configuração da relação professor/a - aluno/a, na educação superior. No total, foram identificadas as seguintes categorias de análise: Formação Acadêmica, com 53,4\% de ocorrência; Formação Docente (18,45\%); Permanência (13,6\%); Educação a distância (EAD), com 10,8\%; Educação Popular (0,97\%); Políticas Públicas (0,97\%); Prática Docente (0,97\%); e Relação Professor/a Aluno/a (0,97\%).

\section{ENTENDENDO A RELAÇÃO PROFESSOR/A - ALUNO/A APARTIR DA FORMAÇÃO ACADÊMICA}

Os aspectos identificados nas produções foram sistematizados nas categorias apresentadas anteriormente, por agrupamento de semelhanças e/ou inter-relação, procurando-se descrever os principais elementos teórico-metodológicos apresentados nos artigos, o que permitiu uma análise de tendências ou características comuns nas produções estudadas, que serão descritas a seguir. Para fins deste artigo, será discutida, de maneira mais aprofundada, apenas a categoria formação acadêmica, 
por apresentar importantes elementos para a análise da categoria central, qual seja a relação professor/a - aluno/a.

Na categoria Formação Acadêmica, observou-se a existência de trabalhos cuja preocupação ou objetivo principal é a discussão acerca da formação dos/as alunos/as de graduação, englobando aspectos ligados ao currículo dos cursos; às competências acadêmicas prévias e adquiridas; às metodologias de ensino (incluindo as TICs) e de avaliação (individual ou mesmo institucional) necessárias para melhoria do processo de ensino-aprendizagem; aos programas acadêmicos de iniciação científica, mobilidade acadêmica internacional, programas de assistência estudantil ou financiamento e sua influência na formação do/a aluno/a; ao engajamento, motivação, identificação ou satisfação dos/as alunos/as em/com seus cursos; às características sociodemográficas e educacionais de alunos/as e sua relação com a formação e com o sucesso escolar, incluindo a análise da realidade ou trajetória de alunos/as cotistas e/ou trabalhadores/as; à qualidade do ensino de graduação e sua relação com o mercado e com a formação para o empreendedorismo; bem como às barreiras que impedem a criatividade dos/as alunos/as em sala de aula e à dimensão afetivo-cognitiva no ambiente de ensino-aprendizagem.

Além dos aspectos gerais apresentados, subdividimos essa categoria em:

a) Formação Acadêmica / Formação Docente, por tratar-se de uma discussão sobre a dimensão afetiva e cognitiva no currículo dos cursos de formação de professores/as, trazendo, de maneira interrelacionada, a discussão da formação discente e docente; a necessidade de investimento em capacitação docente e da avaliação da prática profissional como estratégia de ensino-aprendizagem; a trajetória escolar de professores universitários com deficiência, para entender as razões do seu êxito; os sentidos da avaliação docente, percebidos pelos discentes; uma proposta multidimensional de responsabilidade social, com um trabalho de planejamento, execução e avaliação de ações pedagógicas e de formação docente e técnica; além da discussão sobre democratização, abrangendo $\mathrm{o} / \mathrm{a}$ aluno/a, a formação docente e a infraestrutura do sistema educativo;

b) Acesso, englobando trabalhos que tratam do ingresso de novos públicos (ingressos de escolas públicas) e da necessidade de se discutir e adequar os currículos e políticas institucionais a esses novos/as alunos/as, em sua formação, e trabalhos que tratam das expectativas dos/as alunos/as em relação à universidade;

c) Modelos de Educação Superior, em que é apresentado o modelo da Universidade Federal do ABC (UFABC), como novo modelo pedagógico e as contradições entre o discurso e a prática docente;

d) Permanência, com artigos que tratam da análise do sistema de cotas e dos mecanismos para garantir a aprendizagem e a permanência dos/as cotistas, e apresentam discussões sobre características sociais, econômicas e culturais de alunos/as e suas condições de permanência em cursos, de acordo com a valorização social e com o retorno da sua formação em termos de oportunidades ocupacionais. $\mathrm{Na}$ tabela 1 , a seguir, encontram-se listadas as produções selecionadas e analisadas: 
Tabela 1: Produções sobre a temática Formação Acadêmica

\begin{tabular}{|c|c|}
\hline $\mathrm{N}^{\circ}$ REGISTRO & REFERÊNCIA \\
\hline 2 & Veras, Coelho, Teixeira \& Traverso-Yépez (2018) \\
\hline 8 & Nunes \& Neira (2018). \\
\hline 11 & Tavares \& Gomes (2017) \\
\hline 13 & Miranda \& Ayoub (2017) \\
\hline 16 & Pinho (2017) \\
\hline 17 & Tronchin, Pedro \& Rezende (2017) \\
\hline 19 & Felicetti \& Cabrera (2017) \\
\hline 20 & Faleiro \& Farias (2017) \\
\hline 24 & Oliveira \& Freitas (2017) \\
\hline 25 & Riccio (2017) \\
\hline 27 & Martins \& Ribeiro (2017) \\
\hline 28 & Noro, Roncalli, Medeiros, Farias-Santos \& Pinheiro (2017) \\
\hline 29 & Anjos \& Aguilar-da-Silva (2017) \\
\hline 30 & Chagas \& Pedroza (2017) \\
\hline 31 & Marinho-Araujo \& Almeida (2017) \\
\hline 32 & Brocco (2017) \\
\hline 34 & Conterno \& Lopes (2016) \\
\hline 35 & Pimenta \& Pimenta (2016) \\
\hline 36 & Fontele \& Crisóstomo (2016) \\
\hline
\end{tabular}


DOI: $10.12957 /$ teias.2022.56040

\begin{tabular}{|c|c|}
\hline $\mathrm{N}^{\mathrm{o}}$ REGISTRO & REFERÊNCIA \\
\hline 38 & Lacerda, Ferri \& Duarte (2016) \\
\hline 44 & Francisco, Costa, Hamamoto \& Hafner (2016) \\
\hline 47 & Fujita, Carmona, Shimo \& Mecena (2016) \\
\hline 48 & Marinho-Araujo (2016) \\
\hline 49 & Dutra-Thomé, Pereira \& Koller (2016) \\
\hline 50 & Zago (2016) \\
\hline 52 & Camargo das Neves, Guerreiro \& Azevedo (2016) \\
\hline 53 & Lemos Filho, Bariani, França, Trevisan, Granja, Rodrigues \& Pádua (2016) \\
\hline 54 & Pereira, Carneiro \& Gonçalves (2015) \\
\hline 58 & Marinho-Araujo \& Rabelo (2015) \\
\hline 59 & Nunes \& Neira (2015) \\
\hline 64 & Bertolin \& Marcon (2015) \\
\hline 65 & Fagundes (2014) \\
\hline 66 & Goergen (2014) \\
\hline 69 & Ristoff (2014) \\
\hline 70 & Orlando \& Caiado (2014) \\
\hline 72 & Gonçalves (2014) \\
\hline 75 & Ricoy \& Couto (2014) \\
\hline 81 & Caixeta \& Sousa (2013) \\
\hline 83 & Corrochano (2013) \\
\hline
\end{tabular}


DOI: $10.12957 /$ teias.2022.56040

\begin{tabular}{|c|c|}
\hline $\mathrm{N}^{\circ}$ REGISTRO & REFERÊNCIA \\
\hline 84 & David, Melo \& Malheiro (2013) \\
\hline 86 & Andrade, Gomes, Knobel \& Silva (2012) \\
\hline 87 & Matos, Pimenta, Almeida \& Oliveira (2012) \\
\hline 88 & Haas \& Linhares (2012) \\
\hline 90 & Palazzo \& Gomes (2012) \\
\hline 92 & Baibich \& Sommer (2012) \\
\hline 94 & Costa, Mazzoni, Braccialli \& Moraes (2011) \\
\hline 95 & Brandão (2011) \\
\hline 96 & Costa \& Carvalho (2011) \\
\hline 97 & Dias Sobrinho (2010) \\
\hline 98 & Weber (2010) \\
\hline 99 & Ribeiro (2010) \\
\hline 100 & Antunes, Polito \& Resende (2010) \\
\hline 101 & Alencar \& Fleith (2010) \\
\hline 102 & Guimarães \& Martins (2010) \\
\hline 104 & Leite (2010) \\
\hline
\end{tabular}

Fonte: Dados da pesquisa, 2019. ${ }^{6}$

Para uma discussão mais aprofundada sobre a categoria formação acadêmica e sua interface com a relação professor/a - aluno/ $a$, nossa categoria central, traremos algumas discussões e conclusões dos artigos selecionados.

Inicialmente, foram identificados os resultados do estudo de Adriana Oliveira e Maria Ester Freitas (2017, p. 778), que teve como objetivo “[...] analisar as experiências interculturais de alunos e professores universitários que realizaram programas de mobilidade acadêmica internacional, focalizando os desafios vivenciados, os aspectos facilitadores e os ganhos alcançados". No texto, as autoras destacam as dificuldades enfrentadas pelos intercambistas com as diferenças socioculturais, destacando-se o idioma como importante elemento de dificuldade na adaptação $\mathrm{dos} /$ as alunos/as. Dentre os elementos facilitadores, os/as alunos/as mencionam o apoio de outros intercambistas e dos/as professores/as, destacando-se a experiência de mobilidade como favorecedora para a construção de capital simbólico, desenvolvido a partir do confronto com diferentes desafios, estratégias, enfrentamentos e adaptações necessárias, contribuindo "[...] para o desenvolvimento

${ }^{6}$ Legenda: Formação Acadêmica/Acesso; Formação Acadêmica/Formação Docente; Formação Acadêmica/Modelos de Educação Superior; Formação Acadêmica/Permanência. 
de competências pessoais, interculturais, profissionais e acadêmicas.” (OLIVEIRA; FREITAS, 2017, p. 774). Em síntese, o capital simbólico “[...] caracteriza-se pelo enriquecimento cultural, intelectual e pessoal do indivíduo, que se vê transformado no seu senso de identidade e nos seus valores e suas atitudes socioculturais." (OLIVEIRA; FREITAS, 2017, p. 794). Estendendo-se esses conceitos para as situações enfrentadas pelos/as alunos/as que adentram a universidade pela primeira vez, pode-se supor que haja, também, a construção desse capital simbólico, através das inúmeras experiências nas quais a língua falada na academia em nada se aproxima da linguagem extramuros dos universitários, devendo haver o desenvolvimento de competências semelhantes que possibilitem o enfrentamento e o crescimento pessoal e profissional. Por isso, os elementos de acolhimento dos grupos de alunos/as (pares) e dos/as professores/as, nessa fase de transição, parecem igualmente fundamentais para a aquisição de capital simbólico no ambiente universitário.

Em outro artigo, Letícia Martins e José Luís Ribeiro (2017) discutem a categoria engajamento como indicadora para avaliação da qualidade do ensino superior e consequente sucesso acadêmico do/a aluno/a. No texto, os autores trazem as contribuições de Chickering e Gamson (1987, apud MARTINS; RIBEIRO, 2017, p. 226) que apresentam sete boas práticas de alta qualidade de ensino e aprendizagem: "[...] (i) contato estudante-corpo acadêmico da universidade (ii) aprendizagem ativa (iii) feedback rápido (iv) tempo na tarefa (v) altas expectativas do estudante (vi) respeito pela diversidade nos estilos da aprendizagem (vii) cooperação entre os estudantes". A discussão dos autores apresenta o estado da discussão atual sobre a categoria engajamento, envolvendo inclusive um amplo debate sobre a alocação de recursos institucionais e a organização curricular, que permeia toda a cultura organizacional, para encorajar a participação discente em atividades relevantes e que envolvam persistência, satisfação, aprendizagem e conclusão do curso, de modo que os/as alunos/as desenvolvam a percepção de pertencimento ao ambiente de ensino-aprendizagem, através de interações entre os/as estudantes e seus/as colegas, corpo docente e apoio institucional (MARTINS; RIBEIRO, 2017, p. 226). Há, ainda, necessidade de compreender essa categoria relacionando-a aos "[...] aspectos sociais, culturais e características pessoais que o estudante traz consigo ao ingressar no ensino superior, assim como as suas experiências no campus, o tamanho e a forma de seleção usada para o seu ingresso na universidade." (PORTER, 2006 apud MARTINS; RIBEIRO, 2017, p. 228). E, continua, a análise afirmando:

Strydom, Mentz e Kuh (2010) afirmam que o engajamento do estudante é definido por dois componentes chaves. O primeiro, diz respeito a quantidade de tempo e esforço dedicado pelo estudante em atividades acadêmicas e envolvido em outras experiências que conduzam a resultados de aprendizagem que constituem sucesso do estudante [grifos nossos] O segundo componente, refere-se às maneiras pelas quais as instituições de ensino alocam recursos e oportunizam momentos de aprendizagem, assim como os seus serviços de suporte para tal fim (Kuh, 2005). (PORTER, 2006 apud MARTINS; RIBEIRO, 2017, p. 228-229).

Martins e Ribeiro (2017) mencionam, portanto, que, mais importante do que a instituição e seus recursos, o empenho dos/as estudantes e a dedicação de tempo às atividades acadêmicas são fundamentais para a aprendizagem e permanência no curso, importando menos que o perfil do/a estudante ou da instituição frequentada, segundo outros autores citados no artigo (Pascarella, 2001; Pascarella e Terenzini, 2005; Strydom, Mentz e Kuh, 2010; Kuh, 2005). Destaca-se, também, segundo Kift e Field (2009) como citado em Martins e Ribeiro, (2017), que o currículo do curso de graduação, quando intencionalmente elaborado, pode ampliar o engajamento do/a estudante e sua motivação para aprender, tornando-os ativos em sua aprendizagem. Assim, as instituições devem 
possibilitar ambientes e momentos de lazer "[...] não apenas para promover o equilíbrio entre as atividades acadêmicas, mas, também, para melhorar o nível de engajamento do estudante" (EVANS; HARTMAN; ANDERSON, 2013, apud MARTINS; RIBEIRO, 2017, p. 229).

Por fim, Martins e Ribeiro trazem um diagrama que traduz o engajamento e sua relação com sucesso escolar:

Figura 2: Framework engajamento

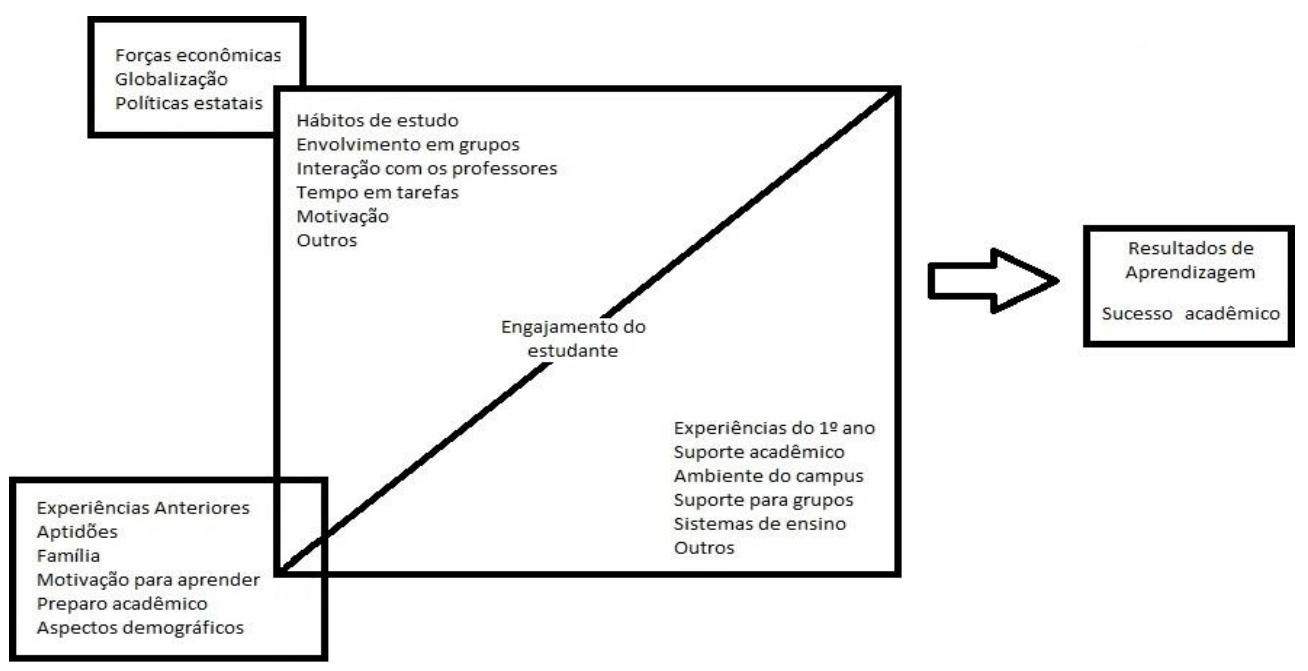

Fonte: Martins e Ribeiro (2017, p. 231). Adaptado de Kuh e colaboradores (2006, p. 8).

Nesse sentido, os modelos explicativos utilizados pelos vários autores citados no artigo de Martins e Ribeiro (2017) têm em comum fazer uma abordagem das experiências ou vivências anteriores do/a aluno/a, incluindo aspectos sociodemográficos e antecedentes escolares; das características e suporte institucionais; das interações com corpo docente e discente e demais membros da instituição; da percepção do/a aluno/a sobre seu ambiente escolar; e da qualidade e quantidade de esforço empreendido para executar as atividades propriamente educacionais.

Outro importante artigo é apresentado por Júlia Chagas e Regina Pedroza (2017, p. 1), sob a fundamentação da Psicologia Histórico-Cultural, de inspiração foucaultiana, tendo por objetivo "compreender de que maneira discursos e práticas patologizantes e medicalizantes se materializam nesse cotidiano e se desdobram em políticas universitárias", contaminados por concepções tradicionais de ensino que tendem a individualizar os problemas escolares, como problemas ou transtornos do/a aluno/a, tornando o ensino ainda mais excludentes e que violam os direitos individuais. Segundo as autoras, há uma certa padronização das ações educativas, baseada em discursos patologizantes e medicalizantes dos problemas ligados à escolarização, impactando de maneira significativa sua formação e vivência acadêmica, ou seja, “[...] É mais uma expressão do atendimento à deficiência e não ao estudante e da redução da pessoa a seu diagnóstico, invisibilizando suas idiossincrasias, potencialidades e contribuições ao processo educativo". Os resultados da pesquisa, apresentados no artigo, trazem à tona "[...] a necessidade de a universidade [...] voltar-se para si mesma e para o estudo de sua própria realidade e das práticas educativas que se realizam nesse espaço.” (CHAGAS; PEDROZA, 2017, p. 7/9).

Em outro artigo, da área da Psicologia do Desenvolvimento Humano, Claisy MarinhoAraújo e Leandro Almeida (2017) ampliam compreensão da categoria competência, em relação aos 
processos formativos pessoal e profissional, na educação superior ${ }^{7}$. Os autores defendem "[...] a noção de competência ancorada na mobilização intencional de diversos recursos próprios ao desenvolvimento humano: processos psicológicos, comportamentos, conhecimentos, afetos, crenças, habilidades, escolhas éticas e estéticas, que devem ser mobilizados pelo sujeito." (MARINHO-ARAÚJO; ALMEIDA, 2017, p. 1). Nesse sentido, o ensino superior é visto como uma oportunidade importante para que os/as alunos/as desenvolvam competências transversais e técnico-científicas, para os diferenciarem em seus perfis profissionais. Citando Dias Sobrinho (2010), Marinho-Araújo (2004) e Vieira e Marques (2014),as autoras defendem uma formação cidadã, na educação superior, que enfoque mais do que a competência técnico-profissional, mas a formação de um profissional comprometido ética e politicamente, crítico em relação à vida social, econômica e cultural (MARINHO-ARAÚJO; ALMEIDA, 2017, p. 2).

Como conclusões dos seus estudos, as autoras defendem a ampliação conceitual da noção de competência, para além da dimensão intersubjetiva, considerando a influência das relações histórico-culturais e sociais, próprias de atividades coletivas como ocorre na educação, em geral, e na educação superior, em particular. Nesse sentido,

\begin{abstract}
A ênfase em processos coletivos não minimiza capacidades, interesses, expectativas, projetos e aspirações particulares dos sujeitos; pelo contrário, de forma dialética, favorece a autonomia no sentido da emancipação das relações alienantes, fortalece opções solidárias e articula a formação educacional e profissional às dimensões ética e sociopolítica. Caracterizar a competência nessa perspectiva ampliada significa incorporar uma historicidade individual e coletiva à consolidação de um processo de desenvolvimento pessoal e profissional competente e criticamente consciente. Nesse sentido, considerar as competências humanas contextualizadas, historicamente definidas, individual e coletivamente constituídas, acompanhadas da mobilização dos recursos gerados nas atividades e relações sociais, pode ser de grande auxílio às inúmeras intervenções profissionais nos contextos educativos. Com efeito, trabalhar competências como uma estratégia de construça do perfil educacional ou profissional esperado apresenta-se como ferramenta essencial ao planejamento da formação na educação superior. Ao mesmo tempo, a dinâmica do desenvolvimento de competências, as mediações socioafetivas, a influência do contexto e das relações devem ser consideradas tanto no momento interpretativo do processo avaliativo quanto, antes, na elaboração dos instrumentos que irão apontar os indicadores acerca de futuros desenvolvimentos de competências. (MARINHO-ARAÚJO; ALMEIDA, 2017, p. 8 , grifos nossos).
\end{abstract}

A partir dessa discussão, os autores propõem uma formação acadêmica e psicossocial, para os estudantes da educação superior, baseada no modelo de avaliação e planejamento por competências, a partir dos princípios da Psicologia do Desenvolvimento.

\footnotetext{
${ }^{7}$ A discussão deste artigo retoma outro trabalho analisado sobre a temática, em que os autores discutem "[...] os referenciais utilizados na compreensão do conceito de competência, com o objetivo de clarificar e ampliar sua abrangência." (MARINHO-ARAUJO; RABELO, 2015, p. 443), visando uma análise crítica das estratégias formativas na educação superior. Outro importante artigo discute o domínio das competências e das habilidades adquiridas que facilitam o desenvolvimento de novas aprendizagens na educação superior e propõe uma intervenção de aconselhamento no processo de transição ensino médio-educação superior, incluindo “[...] as seguintes dimensões: conhecimento prévio, conhecimento do contexto socioeducativo, adaptação ao novo contexto, concepções prévias sobre o ensino superior, informação acadêmica e profissional, motivação, habilidades acadêmicas, competências para a aprendizagem de novas competências, apoio familiar, desempenho escolar, etc.” (FAGUNDES, 2014, p. 521)
} 
No artigo de Ana Karina Brocco (2017), discute-se o significado de realizar um curso superior para os/as estudantes contemplados por políticas voltadas ao acesso e à permanência de estudantes de baixa renda ${ }^{8}$. Os resultados do estudo, feito em uma instituição de ensino superior comunitária de Santa Catarina, apontam que a maioria dos/as alunos/as bolsistas (parcial ou integral) percebem o ensino superior como possibilidade de mobilidade e reconhecimento social, como forma de conseguir boa colocação no mercado de trabalho e, consequentemente, obter uma vida melhor no futuro, incluindo o acesso aos mais diferentes capitais, como possibilidade de superar a condição social da família (BROCCO, 2017, p. 99). Para melhor visualizar essas expectativas, a autora utiliza-se de uma interessante ferramenta, o Wordle 9 , apresentando sua síntese de respostas dos bolsistas na figura 3, a seguir:

Figura 3: Sentidos de Cursar o Ensino Superior para Estudantes Bolsistas (2012-2013).

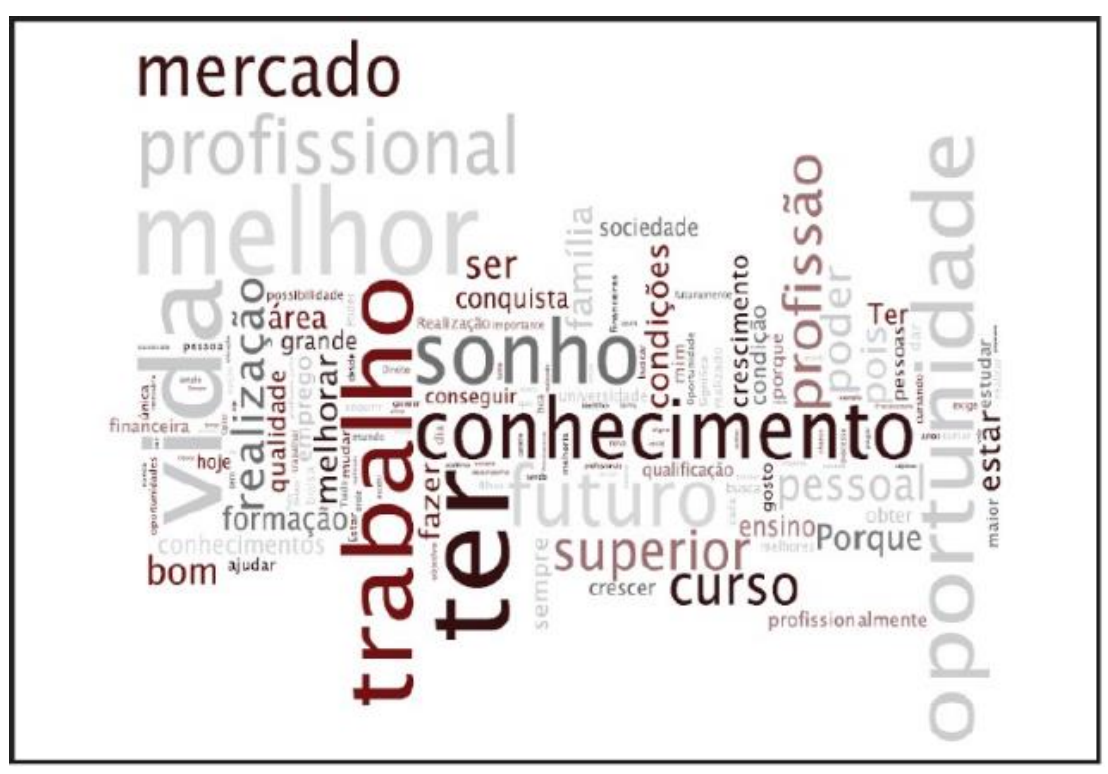

Fonte: Brocco (2017, p. 99).

Para analisar os dados, Brocco (2017, p. 106), utilizando-se dos argumentos teóricos de Thompson (1987), afirma que:

O sentido do ensino superior para os universitários bolsistas pesquisados situase, como sugeriu a teoria thompsoniana, em torno de adaptações, necessidades, expectativas e interesses, constituindo-se, principalmente, como uma vontade de mudar de vida, o que inclui melhorar as condições individuais, e muitas vezes coletivas, abrangendo em maior proporção suas famílias e em menor proporção sua classe social de origem.

Porém, essa vontade de mudar de vida nem sempre se concretiza no cotidiano pós-educação superior, levando a autora a questionar:

\footnotetext{
8 Sobre a presença de novos públicos na educação superior, tem-se também o texto de Corrochano (2013) abordando a realidade de jovens trabalhadores e suas expectativas de acesso ao ensino superior.

9 “'[... programa com o qual é possível criar 'nuvens de palavras' do texto fornecido, destacando aquelas que aparecem com maior frequência.” (BROCCO, 2017, p. 99)
} 
Os egressos desse nível de ensino provenientes de camadas populares, independentemente da instituição que frequentaram, estão na mesma condição de seus colegas de camadas mais altas de ascender a posições significativas no mercado de trabalho? $\mathrm{O}$ acesso à universidade, a um curso superior, é suficiente para dotar pessoas que ingressam com um capital cultural precário de um capital cultural mais amplo? O capital cultural predominante será o institucionalizado, na forma do certificado? Este evidentemente possibilita uma vida melhor, mas muitos terão uma ascensão no plano secundário comparados àqueles que já partiram de outro patamar. (BROCCO, 2017, p. 106)

E finaliza o artigo defendendo a necessidade de valorização do saber, não apenas na educação superior, mas desde a educação básica, trazendo a dimensão do afeto para dentro dos muros universitários e resgatando a concepção de universidade como promotora e divulgadora do conhecimento, para além de uma visão meramente pragmática de mercado e de melhoria das condições de vida (BROCCO, 2017, p. 106).

Ainda sobre a avaliação da formação recebida na universidade, através de uma discussão sobre a relação universidade - mercado de trabalho ${ }^{10}$, ou perspectivas futuras para egressos, Anete Francisco e colaboradores (2016) fizeram um acompanhamento da inserção no mercado de trabalho e continuidade na formação de egressos dos anos 2007 a 2010, do curso de graduação em Enfermagem.

Os resultados mostram alguns aspectos positivos do curso, como uma clara inserção no mercado de trabalho da maioria dos/as egressos/as, com alta empregabilidade, sobretudo na rede pública e a adequação curricular ao cotidiano dos/as egressos/as, sobretudo com o favorecimento dos chamados métodos ativos de ensino-aprendiragem (Aprendizagem Baseada em Problemas - ABP e na problematização, a partir de Paulo Freire) para o desenvolvimento profissional. Como fragilidades, os autores citam o desencontro entre a proposta do curso e a formação de profissionais comprometidos com o SUS, a adaptação às metodologias de ensino empregadas no curso, a deficiência no aprendizado de procedimentos e pouco estímulo à pesquisa (FRANCISCO et al, 2016, p. 494).

Também sobre a discussão de metodologias ativas, Júnia Fujita e colaboradores (2016) relatam a experiência com o uso da metodologia da problematização, no ensino sobre brinquedo terapêutico, também na Graduação de Enfermagem, com apoio do Arco de Maguerez e suas cinco etapas, conforme figura 4 , a seguir:

\footnotetext{
10 Também discutem a formação acadêmica e docente, na educação superior, e a relação entre o conhecimento e o mercado de trabalho, o artigo de Goergen (2014, p. 461), que tem como ponto de partida, "[...] a relevância do uso intensivo da ciência e tecnologia para a vida social, política e econômica na sociedade contemporânea", fazendo uma análise crítica entre o discurso do conhecimento instrumental, útil e mercadológico e a tarefa crítico-reflexiva e formativa das novas gerações, que a educação superior deveria assumir.
} 
Figura 4: Arco de Maguerez (Bordenave e Pereira, 2005)

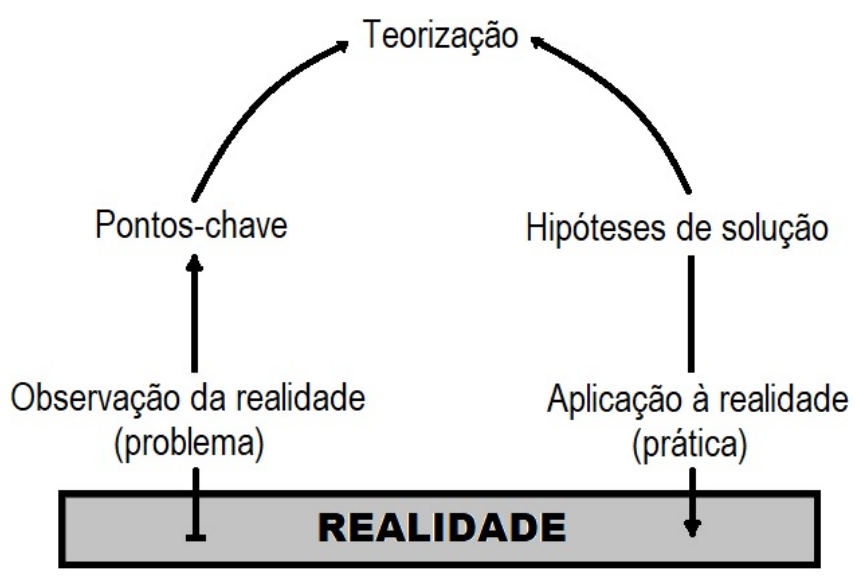

Fonte: Fujita e colaboradores (2016, p. 233).

O princípio que fundamenta as metodologias ativas é a autonomia (FREIRE, 2006, apud FUJITA et al., 2016, p. 241) e a metodologia empregada por Fujita e colaboradores (2016) mostrouse significativa, permitindo a interligação teoria-prática, em um modelo de educação mais dialógica, com a construção coletiva do conhecimento, o estímulo à criatividade ${ }^{11}$ e ao pensamento crítico, podendo colaborar para a formação profissional mais humanizada, solidária e condizente com a realidade de atuação dos futuros profissionais.

Ainda na linha das metodologias ativas, destaca-se o trabalho de María Carmen Ricoy e Maria João Couto (2014) que estudam a percepção dos/as alunos/as recém-integrados/as ao ensino superior, na Espanha, sobre as boas práticas educativas com as Tecnologias da Informação e Comunicação (TIC). Os resultados apontam que as TIC são associadas às boas práticas (dispositivos e aplicativos atuais), sem questionamento de sua combinação com estratégias didáticas inovadoras. Dentre os benefícios apontados estão: o acesso à internet, a comunicação, a publicação e difusão de conteúdos em formatos variados. Como obstáculos citados estão: o elevado custo econômico de alguns dispositivos, as dificuldades técnicas, a distração que podem produzir, a perda de contato pessoal e de tempo, e aspectos inerentes a sua futura profissão.

Para finalizar, o trabalho de Arnaldo Lemos Filho e outros (2016) apresentam um novo método de análise da série histórica dos resultados derivados das respostas dos/as estudantes a um instrumento com 19 questões, distribuídas em cinco categorias: plano de ensino da disciplina, desenvolvimento da disciplina, avaliação da aprendizagem, formação do/a aluno/a, postura do/a professor/a, conforme tabela 2 , a seguir:

11 Sobre criatividade, ver também Alencar e Fleith (2010). 
DOI: $10.12957 /$ teias.2022.56040

Tabela 2: Categorias e Aspectos Preservados na Série Histórica

\begin{tabular}{|c|c|}
\hline Categorias & Aspectos \\
\hline \multirow{2}{*}{$\begin{array}{l}\text { 1. Plano de Ensino da } \\
\text { Disciplina }\end{array}$} & 1. Apresentação e Discussão do Plano da Disciplina \\
\hline & 2. Cumprimento do Plano da Disciplina \\
\hline \multirow{8}{*}{$\begin{array}{l}\text { 2. Desenvolvimento } \\
\text { da Disciplina }\end{array}$} & 3. Organização \\
\hline & $\begin{array}{l}\text { 4. Habilidade de ministrar o conteúdo adequadamente e atingir seus } \\
\text { objetivos. }\end{array}$ \\
\hline & 5. Domínio do Conteúdo \\
\hline & 6. Exposição lógica e clara \\
\hline & 7. Ministrar uma boa aula \\
\hline & $\begin{array}{l}\text { 8. Uso de procedimentos metodológicos e/ou recursos didáticos } \\
\text { diversificados }\end{array}$ \\
\hline & 9. Interdisciplinaridade \\
\hline & 10. Diálogo/perspectivas com a realidade \\
\hline \multirow{2}{*}{$\begin{array}{l}\text { 3. Avaliação da } \\
\text { Aprendizagem }\end{array}$} & 11. Avaliação coerente da aprendizagem do aluno \\
\hline & 12. Proposição e/ou adoção de critérios de avaliação processual \\
\hline \multirow{2}{*}{ 4. Formação do Aluno } & 13. Incentivo à autonomia intelectual do aluno \\
\hline & 14. Contribuição para formação integral do aluno \\
\hline \multirow{4}{*}{$\begin{array}{l}\text { 5. Postura do } \\
\text { Professor }\end{array}$} & 15. Exigência \\
\hline & 16. Liderança \\
\hline & 17. Postura ética e de respeito na relação professor - aluno \\
\hline & 18. Presença às aulas (Assiduidade) \\
\hline
\end{tabular}


Fonte: Lemos Filho e colaboradores (2016, p. 227).

As questões foram avaliadas pelos/as alunos/as em quatro indicadores de qualidade dos aspectos tomados: excelente, bom, razoável e insatisfatório. Os/as alunos/as também foram divididos em quatro dimensões de acordo com a qualidade de participação do alunado no processo avaliativo em: Participação insatisfatória (até 24,99\%); Participação satisfatória (25\% a 39,99\%); Participação significativa (40\% a 59,99\%); Participação muito significativa (acima de 60\%). Os dados apresentados constituem-se em importante instrumento para a melhoria da qualidade de ensino em uma instituição, tornando-se um modelo e um referencial visual para o reconhecimento rápido, de consulta e identificação, por gestores/as e docentes, de situações de excelência tanto quanto de cenários de atenção e alerta institucional.

\section{CONSIDERAÇÕES FINAIS}

Os artigos analisados permitem a construção de um rico referencial teórico-metodológico para subsidiar as análises sobre a permanência na educação superior, a partir de uma relação complexa que se estabelece entre os sujeitos diretamente envolvidos no processo de formação universitária: alunos/as e professores/as, dando ênfase especial ao elemento central do processo ensino-aprendizagem, qual seja, o/a aluno/a, razão de todo aprimoramento e construção de metodologias, processos, recursos e técnicas de ensino, assim como sujeito fundamental para a formação educacional que entendemos ser base para uma sociedade mais justa e igualitária.

Nosso olhar, focado na formação que o/a aluno/a recebe, destacou os elementos importantes apresentados pelos autores, nessa revisão bibliográfica, envolvendo uma discussão sobre: o currículo dos cursos; as competências acadêmicas prévias e adquiridas; as metodologias de ensino (incluindo as TICs) e de avaliação, identificação ou satisfação dos/as alunos/as em/com seus cursos; as características sociodemográficas e educacionais de alunos/as; a qualidade do ensino de graduação; a relação com mercado de trabalho e formação para o empreendedorismo; as barreiras que impedem a criatividade dos/as alunos/as em sala de aula; a dimensão afetivocognitiva no ambiente de ensino-aprendizagem; os programas acadêmicos de iniciação científica; a mobilidade acadêmica internacional, de assistência estudantil ou financiamento; entre outros.

Entretanto, as seguintes categorias de análise foram encontradas e consideradas bastante pertinentes aos nossos futuros estudos sobre a permanência na educação superior: a competência, o capital simbólico, o engajamento, a relação formação e mercado de trabalho, os métodos ativos de aprendizagem, além do importante modelo de avaliação institucional, apresentado por Lemos Filho e colaboradores (2016).

Esperamos que os trabalhos aqui referenciados sejam caminhos fundamentais para os/as pesquisadores/as interessados/as, no sentido de ampliarem os debates e verticalizarem os estudos, com novos elementos para a construção do conhecimento. 


\section{REFERÊNCIAS}

ALENCAR, Eunice M. L. Soriano de; FLEITH, Denise de Souza. Criatividade na educação superior: fatores inibidores. Avaliação: Revista da Avaliação da Educação Superior, Campinas; Sorocaba, SP, v. 15, n. 2, p. 201-206, jul. 2010.

BROCCO, Ana Karina. Aqui em casa a educação é muito bem-vinda: significado do ensino superior para universitários bolsistas. Revista Brasileira de Estudos Pedagógicos, Brasília, v. 98, n. 248, p. 94-109, jan. 2017.

CASTELO BRANCO, Uyguaciara Veloso; JEZINE, Edineide Mesquita Araújo; NAKAMURA, Paulo Hideo. Alguns indicadores de permanência/abandono na educação superior: elementos para o debate. In: CHAVES, V. L. J; MAUÉS, O. C.; HAGE, S. M. (org.). Expansão privado-mercantil da educação superior no Brasil. Campinas: Mercado das Letras, p. 259-286, 2016.

CHAGAS, Julia Chamusca; PEDROZA, Regina Lúcia Sucupira. Patologização e Medicalização da Educação Superior. Psicologia: Teoria e Pesquisa, Brasília, v. 32, n. 28, p. 1-10, mar. 2017.

CORROCHANO, Maria Carla. Jovens trabalhadores: expectativas de acesso ao ensino superior. Avaliação: Revista da Avaliação da Educação Superior, Campinas; Sorocaba, SP, v. 18, n. 1, p. 23-44, mar. 2013.

FAGUNDES, Caterine Vila. Percepção dos estudantes universitários acerca do acesso à educação superior: um estudo exploratório. Revista Brasileira de Estudos Pedagógicos, Brasília, v. 95, n. 241, p. 508-525, dez. 2014.

FRANCISCO, Anete Maria et al. Avaliação da formação de enfermeiros: o reflexo dos métodos de ensino-aprendizagem e pressupostos curriculares na prática profissional. Avaliação: Revista da Avaliação da Educação Superior, Campinas; Sorocaba, SP, v. 21, n. 2, p. 479-502, jul. 2016.

FREIRE, Paulo. Pedagogia do oprimido. Rio de Janeiro: Paz e Terra, 1987.

FUJITA, Júnia Aparecida Laia da Mata et al. Uso da metodologia da problematização com o Arco de Maguerez no ensino sobre brinquedo terapêutico. Revista Portuguesa de Educação, Minho-PT, v. 29, n. 1, p. 229-258, jun. 2016.

GOERGEN, Pedro. Tecnociência, pensamento e formação na educação superior. Avaliação: Revista da Avaliação da Educação Superior, Campinas; Sorocaba, SP, v. 19, n. 3, p. 561-584, nov. 2014.

LEMOS FILHO, Arnaldo et al. Avaliação do ensino: modelo de análise da série histórica de resultados. Avaliação: Revista da Avaliação da Educação Superior, Campinas; Sorocaba, SP, v. 21, n. 1, p. 221-245, mar. 2016.

MARINHO-ARAUJO, Claisy Maria \& RABELO, Mauro Luiz. Avaliação educacional: a abordagem por competências. Avaliação: Revista da Avaliação da Educação Superior, Campinas; Sorocaba, SP, v.20, n.2, p.443-466, jul. 2015.

MARINHO-ARAUJO, Claisy Maria; ALMEIDA, Leandro S. Abordagem de competências, desenvolvimento humano e educação superior. Psicologia: Teoria e Pesquisa, Brasília, v. 32, n. 212, p. 1-10, mar. 2017.

MARTINS, Letícia Martins; RIBEIRO, José Luís Duarte. Engajamento do estudante no ensino superior como indicador de avaliação. Avaliação: Revista da Avaliação da Educação Superior, Campinas; Sorocaba, SP, v. 22, n. 1, p. 223-247, abr. 2017.

MOROSINI, Marília Costa et al. A evasão na Educação Superior no Brasil: uma análise da produção de conhecimento nos periódicos Qualis entre 2000-2011. ICLABES. Primera Conferencia 
Latinoamericana sobre el Abandono en la Educación Superior. Editora E.U.I.T. de Telecomunicación, 2012. Disponível em: http://hdl.handle.net/10923/8762. Acesso em 26 mai. 2019.

OLIVEIRA, Adriana Leônidas de; FREITAS, Maria Ester de. Relações interculturais na vida universitária: experiências de mobilidade internacional de docentes e discentes. Revista Brasileira de Educação, Rio de Janeiro, v. 22, n. 70, p. 774-801, jul. 2017.

RICOY, María Carmen; COUTO, Maria João V. S. As boas práticas com TIC e a utilidade atribuída pelos alunos recém-integrados na universidade. Educação e Pesquisa, São Paulo, v. 40, n. 4, p. 897 912, fev. 2014.

SIRINELLI, Jean François. Os Intelectuais. In: RÉMOND, R. (org.). Por uma bistória política. Rio de Janeiro: Editora FGV, 2003.

Submetido em novembro de 2020 Aprovado em abril de 2021

\section{Informações da autora}

Uyguaciara Veloso Castelo Branco

Professora Associada IV do Programa de Pós-Graduação em Políticas Públicas, Gestão e Avaliação (MPPGAV), da Universidade Federal da Paraíba (UFPB)

E-mail: uyguaciara@gmail.com

ORCID: http://orcid.org/0000-0003-3595-1415

Link Lattes: http://lattes.cnpq.br/7940523057526487 